\title{
Linguistic Variation in the Minimalist Framework
}

\author{
Ed. by M. Carme Picallo
}

Oxford: Oxford University Press, 280 pages. ISBN: 978-0-19-870289-4

Received: $18-10-14$

Accepted: 25-11-14

\author{
Reviewed by Mireia Marimon \\ Universitat Pompeu Fabra
}

The present volume offers a broad perspective of the current state of affairs in the matter of syntactic variation within the Minimalist theory (cf. Chomsky 1995) and presents different current theories and perspectives about the intricacies of this old and ever-present matter. This is certainly the aim of this volume, which is accomplished in a more than satisfactory fashion. As might be expected, all authors that contribute to this volume have a main common goal behind (which is perceivable and obvious): to understand how language is organized, how it works, and how variation and linguistic phenomena operate. Following this line of action, the central topics that are discussed in this volume can be listed as follows:

(i) The notion and the role of "Parameters" in the current linguistic theories

(ii) Connections between morphology, variation, and the lexicon

(iii) The explicitness and the conditions imposed by the syntactic component and the interfaces it is connected to

Even though these are the main topics that all authors try to focus on, it is hard just to address the issue of syntactic variation. Since a lot of questions arise while developing some theories, many different phenomena are considered and discussed throughout the chapters. Even within the same theoretical framework, different ideas and proposals can be found in the volume. Most of the authors refer and give feedback to other authors' contributions; some of them include or reject ideas from the previous ones and, as a result, we can see mixed theoretical models. This means that, although the volume is based on a workshop ${ }^{1}$ and the chapters are essentially related to the speakers' conferences, most of them were modified by the author with the discussions that took place during the workshop, which make the volume even more appealing and helps to establish connections between the chapters. However, due to the high number of chapters and different authors, sometimes discussions may be hard to follow.

From an external and objective point of view, Picallo's introduction to the volume provides a theoretical background of the so-called Principles and Parameters framework and an overview of the different chapters of the book. She

Linguistic Variation in the Minimalist Framework, held at Casa de la Convalescència (Barcelona), 14-15 January 2010. 
explains the two opposite (and sometimes complementary) main views of the volume; while the contributions in the first part support parametric approaches, the ones in the second part give syntax a less important role in variation phenomena and rule out the notion of "parameter". Regarding the conclusions made by Picallo at the end of the edition, she is to be applauded for her attempt of contextualizing, unifying, and trying to establish a guiding principle to link the numerous contributions. Given the length of the contributions included, they will be shortly summarized here.

In the first part of the volume, Luigi Rizzi convincingly shows the problems with the model of "parameters as specifications on principles" and makes the final assumption that the locus for their expression is the functional lexicon. Consequently, he deals with the size of the set of parameters (there are many more parameters than initially thought). As a final point, he defends that each parameter enters into complex interactions that lead to complex patterns of variation. For example, the property of null subject pronoun interacts with special properties of subjects, such as the obligatoriness of the subject position in the clausal structure.

Mark C. Baker also concludes that there is variation and parameterization (in systems of morphological case). However, he focuses on cross-linguistic variation in case-marking and, illustrating his theory with plenty of useful examples, argues for two ways of assigning morphological case in different languages. In Ian G. Holmberg and Anders Roberts' contribution, the same conclusion is reached. The starting point of these authors is the existence of the notion of "parameter", where they follow Chomsky's proposal that there are three factors that are key to explain the emergence not only of parametric variation, but also many other linguistic phenomena like passives, which involve Agree and the nature of "A' movement" (cf. Chomsky 2005). The point they want to make is that syntactic variation must exist, since "the same thought" can be externalized by different syntactic mechanisms into two different ways.

Anna Cardinaletti hypothesizes that parameters are limited to the functional lexicon, like Rizzi, and presupposes that those lexical items have an impact on the core computational operations. She proves so by showing crosslinguistic differences in the location of the verb (in respect to the subject) in different languages and also by the optionality of certain syntactic rearrangements that do not look like mere phonological facts. Ricardo Extepare addresses a possible effect of language external pressures, concretely syntactic variation issues related to a case of diachronic change resulting from Basque-French contact (the types of predicates in dative marking constructions).

Michal Starke takes an approach based on the Nanosyntax framework and formulates a proposal that can account for variation based on the syntactic properties that lexical stored elements have. The importance of the lexicon is again emphasized, like in other previous contributions in this volume.

In the second part of the volume, contributions generally support a different notion of "parameter" and do not give such an important role to syntactic factors in variation processes, but to external(ization) conditions. In Cedric Boeckx's contribution, variation is seen as inevitable and, although he shares the existence of a Universal Grammar (UG) by all the spearkers at the workshop, he refuses the traditional notion of "parameter" for a number of reasons. Boeckx 
concludes that parameters are "empty of content" because, among other reasons, of their dependency upon Principles (dramatically reduced in recent years) and their unsatisfactory arguments to solve Plato's problem.

David Adger attempts to connect linguistic theory with sociolinguistic work on language variation. The author pays attention to internal factors in order to account for variation; he points out the frequency factor in the language acquisition process and also addresses individual variation. Finally, Sjef Barbiers takes the frequency factor into account in doubling particle variation phenomena in the case of Dutch (and its dialects). He explores the Doubling and Deletion Hypothesis in cases like " $A l$ tien boeken heft hej al" (Eng. "He has already ten books') and "Alleen Jan ken ik (*alleen) (En. 'I only know John'). Whereas the focus particle al allows doubling, the particle alleen does not. Barbiers concludes that syntactic doubling is necessary for full interpretation and that it is a core property of natural language.

Overall, this book forces the reader to rethink syntax from the ground up and provides a valuable overview and interesting empirical coverage of a rich area of research, as language variation is. Linguistic variation is one of the main controversial topics in linguistics and this volume proves so. Many different views about the existence and the limits of variation can be found and interestingly supported by more or less convincing arguments in this edition. In my opinion, this volume can have far-reaching consequences and inspire future research; it is also stated by the editor and most contributors that work still needs to be done in this field. For these reasons, I strongly recommend it to any linguist or specialist interested in the subject.

\section{References}

Chomsky, Noam. 1995. The Minimalist Program. Cambridge, MA: MIT Press.

Chomsky, Noam. 2005. "Three Factors in Language Design". Linguistic Inquiry 36: 1-22. http://dx.doi.org/10.1162/0024389052993655 